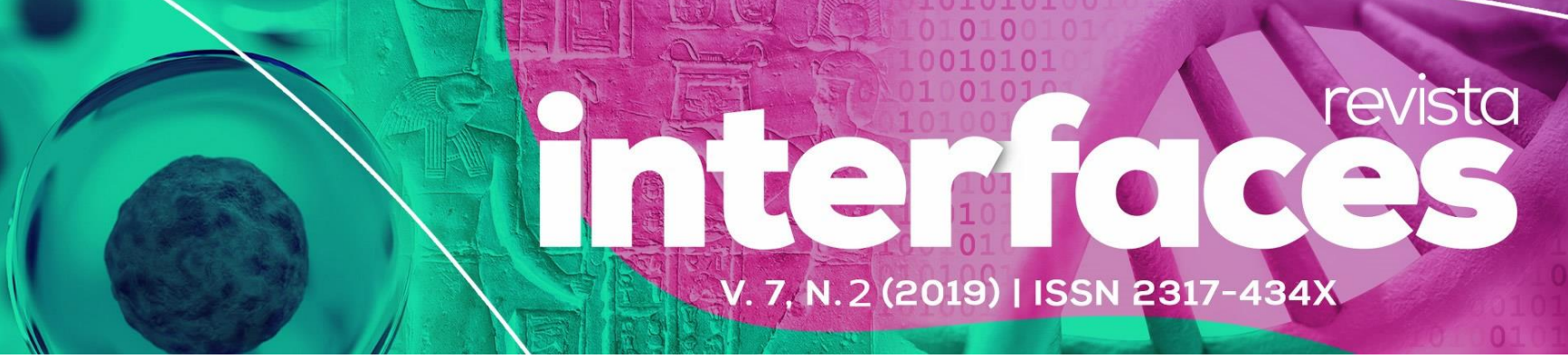

\title{
ECOLOGIA DAS POPULAÇÕES DE GEITLERINEMA E PLANKTOTHRIX EM ECOSSISTEMA DE ÁGUA DOCE
}

\author{
ECOLOGY OF GEITLERINEMA AND PLANKTOTHRIX POPULATIONS IN FRESHWATER \\ ECOSYSTEM
}

DOI: 10.16891/2317-434X.v7.e2.a2019.pp274-281

Recebido em: 25.08.2019 / Aceito em: 20.09.2019

Elielson Francisco Fernandes Ferreira*, Fábio Henrique Portella Oliveira

Centro Universitário São Miguel

*E-mail: elielson-francisco@hotmail.com

\section{RESUMO}

As cianobactérias são bactérias gram-negativas com capacidade fotossintetizante, fazendo parte do fitoplâncton onde compõem um filo com grande diversidade de organismos, tanto morfológica como ecológica. Algumas espécies filamentosas apresentam diversas estratégias fisiológicas e ecológicas, que permitem melhor competição e sobrevivência nos ecossistemas aquáticos. Dentre estas, pode-se citar a produção de células especializadas como os acinetos e heterocitos, e tolerância à baixa luminosidade. Esse estudo teve como objetivo analisar as populações de Geitlerinema e Planktothrix. Foi desenvolvido em um reservatório eutrófico localizado na região Metropolitana de Recife (Pernambuco-Brasil) no período de Julho à Fevereiro, sendo realizadas coletas mensalmente, levando em consideração as variais abióticas e antrópicas, na qual foi escolhido dois pontos distantes um do outros onde foram nomeados como Ponto 1 e 2. Durante o período de monitoramento foi possível observar que Planktothrix, em períodos de sombreamento, apresentou maiores valores de densidade, enquanto Geitlerinema predominou em períodos mais secos e com maior luminosidade.

Palavras chave: Ecologia; Floração; Cianobacterias

\begin{abstract}
Cyanobacteria are gram-negative bacteria with photosynthetic capacity, being part of the phytoplankton where they make up a phylum with great diversity of organisms, both morphological and ecological. Some filamentous species have several physiological and ecological strategies that allow better competition and survival in aquatic ecosystems. These include the production of specialized cells such as acinides and heterocytes, and tolerance to low light. This study aimed to analyse the populations of Geitlerinema and Planktothrix. It was developed in a eutrophic reservoir located in the metropolitan region of Recife (Pernambuco-Brazil) from July to February, being collected monthly, considering the abiotic and anthropic variables, in which two points apart from each other were chosen. named as Point 1 and 2. During the monitoring period it was possible to observe that Planktothrix, in shading periods, presented higher density values, while Geitlerinema predominated in drier and brighter periods.
\end{abstract}

Keywords: Ecology; Bloom; Cyanobacterias. 


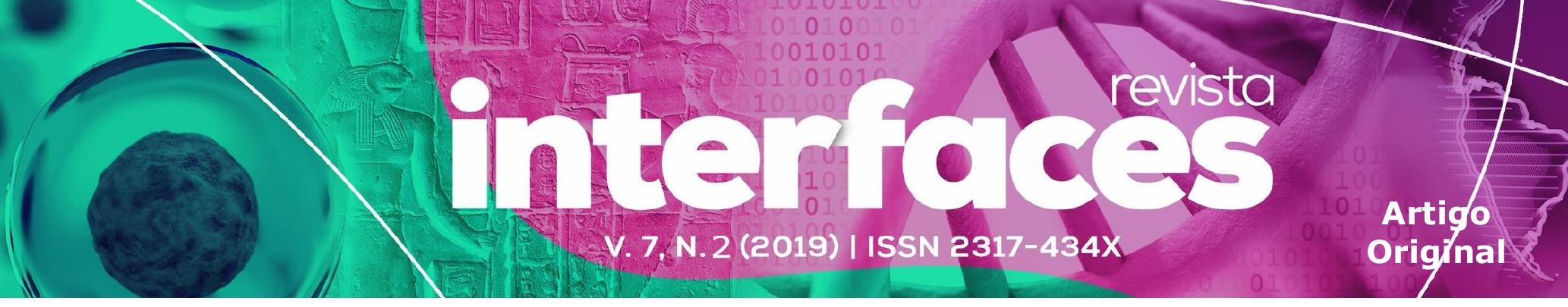

Figura 2. Pontos de coleta

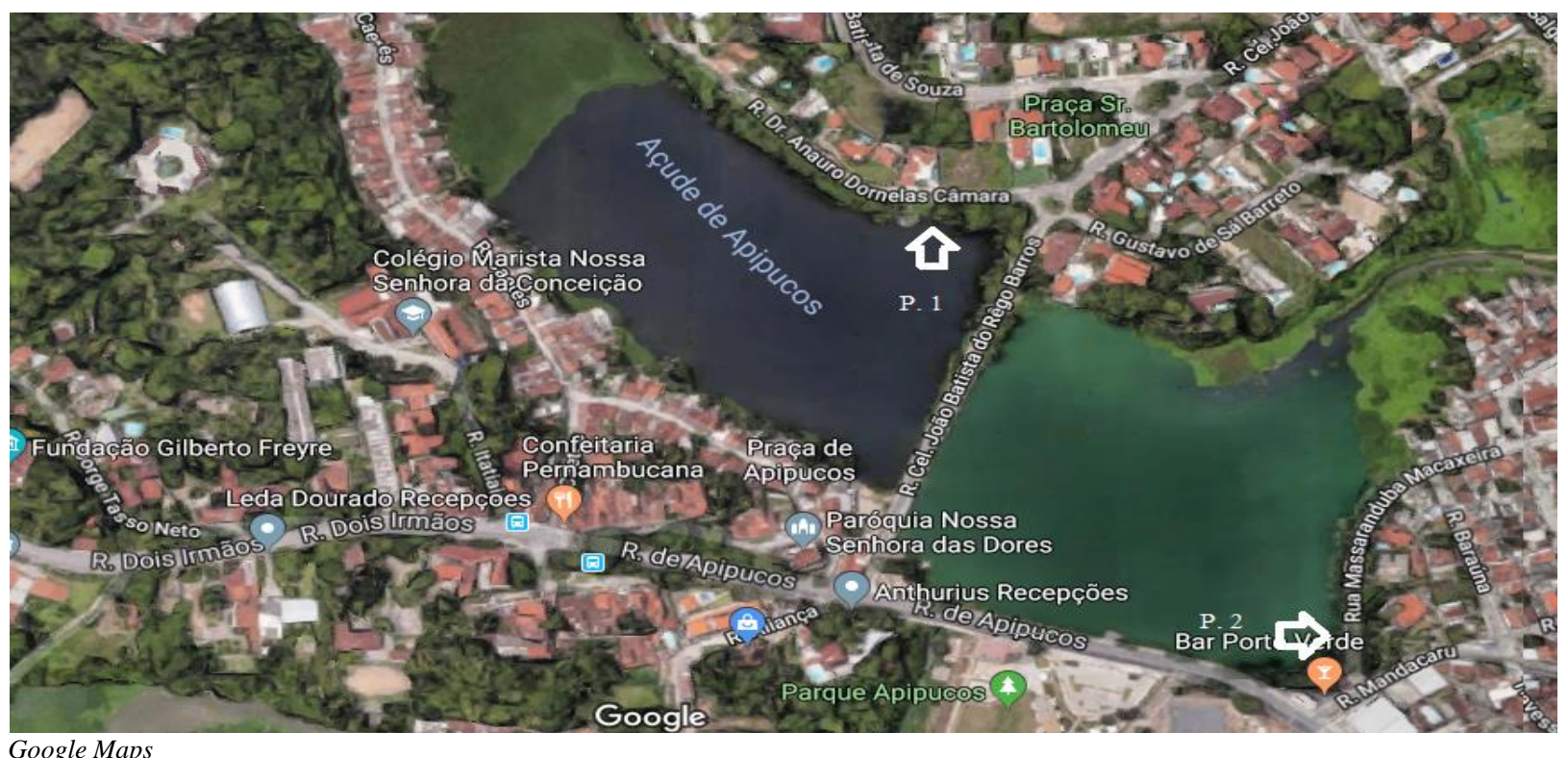

As amostras foram coletas em frascos de vidro tipo âmbar (Figura 3), e logo em seguida preservadas em formaldeído a $4 \%$ e refrigeradas à temperatura de $4^{\circ} \mathrm{C}$. Para as análises qualitativas e quantitativas das populações de cianobactérias, as amostras foram concentradas e analisadas em microscópio invertido (aumento de 200x), utilizando câmaras de Sedgewick-
Rafter (Figura 4). As análises de $\mathrm{pH}$, cor e turbidez foram realizados com auxílio de um potenciômetro (Hach®), colorímetro (Hach®) e tubidímetro (Hach $\left.{ }^{\circledR}\right)$, respectivamente, de acordo com APHA (2012). Para identificação dos organismos, foi utilizada a chave dicotômica descrita por Bicudo (2006) e Sant'anna (2012).
Figura 3. Vidro do tipo âmbar

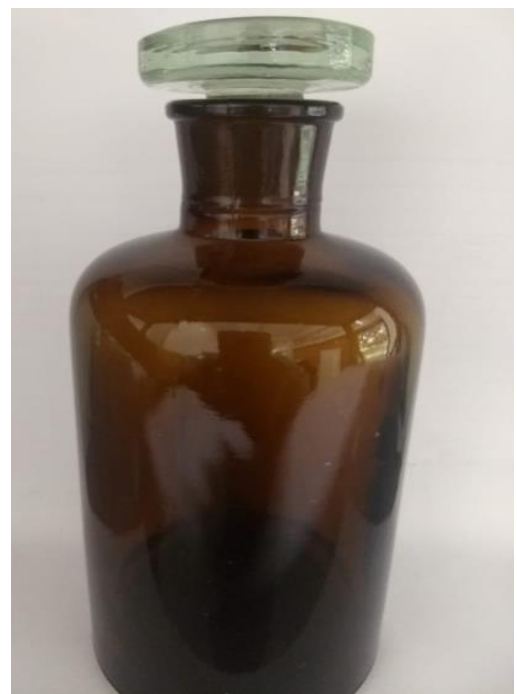

Figura 4. Equipamentos de pipetagem

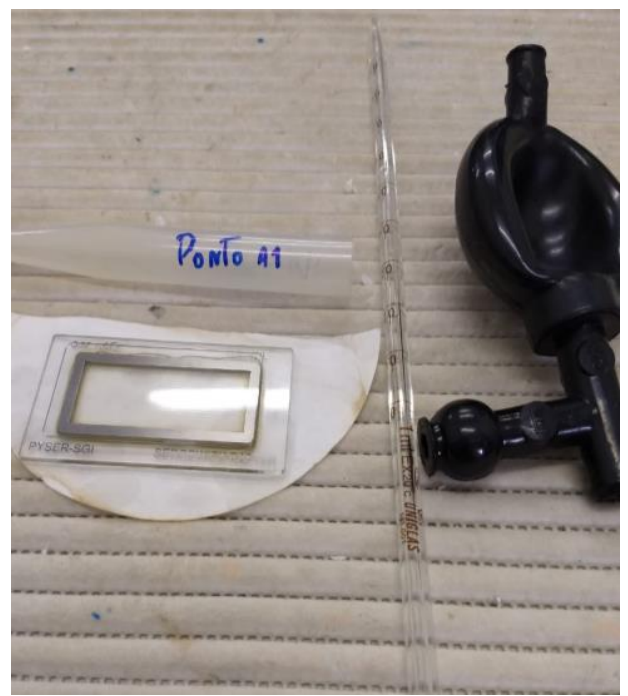




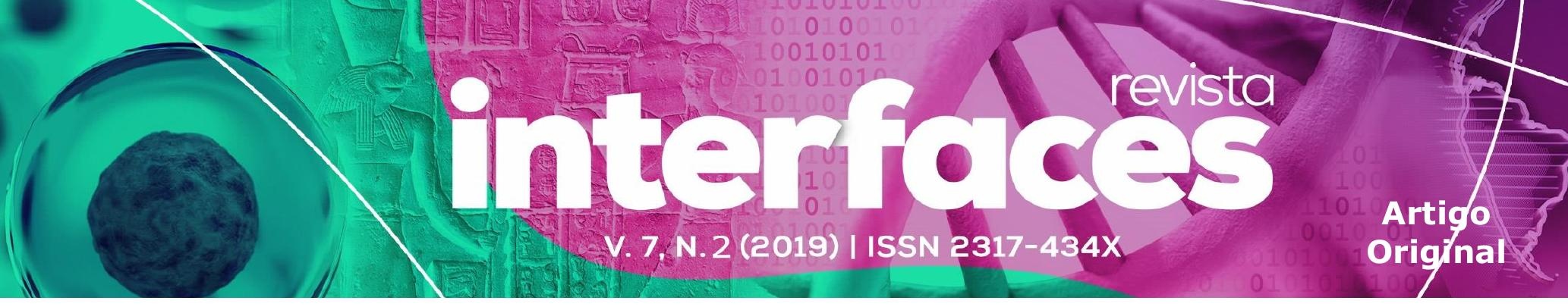

Pernambuco. Vigilância Sanitária Em Debate: Sociedade, Ciência \& Tecnologia, 4(1), 20-26. https://doi.org/10.3395/2317269x.00628

RECIFE. Lei ${ }^{\circ}$ 16.609/2000, de 29 de Dezembro de 2000. Altera o Zoneamento da cidade do Recife, Institui a Unidade de Conservação Açude de Apipucos, e dá Outras Providencias. (Leis Municipais). Disponível

em:

$<$ https://leismunicipais.com.br/a1/pe/r/recife/leiordinaria/2000/1661/16609/lei-ordinaria-n-16609-2000-alterao-zoneamento-da-cidade-do-recife-institui-a-unidade-deconservacao-acude-de-apipucos-e-da-outrasprovidencias?q=16609>. Acesso em: 26 junho 2019

SANT'ANNA, C.L. Atlas de cianobactérias e microalgas de águas continentais brasileiras. São Paulo: Instituto de Botânica, 2012.

SU, M.; YU, J.; ZHANG, J.; CHEN, H.; AN, W.; VOGT, R.D.; ANDERSEN, T.; JIA, D.; WANG, J. YANG, M.; MIBproducing cyanobacteria (Planktothrix sp.) in a drinking water reservoir: distribution and odor producing potential. water research, v.68, p.44-453, 2015. 